\title{
UNIVERSIDADES MERCANTIS a institucionalização do mercado universitário em questão
}

\author{
Adolfo Ignacio Calderón \\ Sociólogo, Doutorando em Ciências Sociais na PUC-SP
}

\begin{abstract}
Resumo: O sistema universitário brasileiro começou a vivenciar uma profunda transformação a partir de dois fatos concretos: a emergência de instituições que denominamos como universidades mercantis e a institucionalização do mercado de ensino universitário. No presente artigo, tendo como referência a realidade do Município de São Paulo, abordaremos a complexidade destes processos, fenômenos novos para a realidade brasileira que se legitimam com a crise fiscal do Estado, sob a hegemonia neoliberal. Palavras-chave: ensino superior; universidade particular; educação no Brasil.
\end{abstract}

$\mathrm{O}$ sistema universitário brasileiro começou a vivenciar a partir do início da década de 90 uma grande revolução no que diz respeito às opções para os cidadãos clientes-consumidores no campo acadêmico-universitário. O cenário das universidades paulistanas - até então dominado pelas universidades públicas e pelas de cunho confessional - viu-se significativamente alterado com a entrada de um novo ator: as universidades particulares com explícitos fins lucrativos, geridos enquanto empresas educacionais, oferecendo produtos e serviços de acordo com a demanda do mercado, instituições estas que denominaremos universidades mercantis.

São essas universidades que estão dinamizando o mercado de ensino do terceiro grau, um mercado que não era visto enquanto tal, mas que está se revelando muito grande, bastante lucrativo e competitivo, ampliando assim a prateleira de opções para os diversos perfis do consumidor.

Essa realidade traz para as ciências sociais desafios teóricos em sua compreensão, ao revelar multiplicidade de análises com implícitas opções político-ideológicas, bem como uma grande polarização teórica.

No meio acadêmico ainda existem autores que se prendem a modelos interpretativos os quais impossibilitam aceitar a existência de universidades com diversos perfis. Insiste-se em falar em "Universidade Brasileira" como si- nônimo de universidade pública, gratuita, supostamente equacionadora do ensino, na pesquisa e na extensão. Nesse sentido, torna-se difícil aceitar afirmações categóricas, idealizadoras da universidade enquanto instituição social, adotadas por muitos autores que se fixam no paradigma social-universalista, fruto do Estado Social emergente no pós-guerra, defensores da universidade pública e do ensino universitário como direito social, atividade não-lucrativa e sua conseqüente provisão estatal.

$\mathrm{O}$ estudo do que denominamos universidades mercantis revela a utilização de novos termos e categorias até há pouco tempo impensáveis de serem utilizados na abordagem do ensino superior. Dois deles utilizamos no início deste ensaio: mercado de ensino e cliente-consumidor. É interessante verificar a rejeição de amplos setores acadêmicos à possibilidade de se compreender o aluno universitário como um cliente-consumidor, a aversão de se considerar o ensino universitário como um produto/serviço comercializado. São questões cujo caráter polêmico se evidencia nos estudos e pesquisas produzidos sobre o ensino superior privado. Como aponta Sampaio (1998:167168), boa parte da literatura acadêmica sobre a expansão do ensino superior no País traz consigo uma visão negativa do ensino superior privado e, em geral, esses estudos "partem do princípio que o Estado deve universalizar o ensino superior público e gratuito e que, portanto, a oferta privada é um desvio indesejado do sistema. Conside- 
ram que somente instituições públicas, mantidas com recursos exclusivos do Estado, podem corresponder à missão da universidade: formar profissionais críticos, desenvolver o conhecimento e transformar a sociedade (...) A oferta privada de ensino superior é um mal que se propagou no sistema em virtude da política de favorecimento à iniciativa privada que vigorou durante o regime militar no País". A autora afirma que em tempos de democracia "a conspiração dos governos militares que promoveu a expansão do ensino privado é substituída pela conspiração neoliberal orientada por organismos internacionais". Nessas análises, "o ensino superior privado tem objetivos fundamentalmente mercantis (...), operando, em geral, como uma fábrica de diplomas".

São muitas as questões vinculadas à proliferação das universidades mercantis que devem ser aprofundadas: a crise da universidade pública, o redimensionamento do papel do Estado, as funções, a qualidade e as formas de gestão das universidades privadas, etc. No presente ensaio, tendo como referência a realidade do Município de São Paulo, abordaremos e aprofundaremos somente um tópico: a institucionalização do mercado de ensino universitário, fenômeno novo para a realidade brasileira que se legitima com a crise fiscal do Estado, sob a hegemonia neoliberal.

\section{QUANDO NOVOS ATORES ENTRAM EM CENA}

As universidades no Brasil surgiram somente no século XX pela ação do Estado. Até 1968 - início da grande Reforma Universitária que implantou o sistema atualmente vigente, impulsionado pelo regime militar - o sistema universitário brasileiro estava dividido entre universidades públicas financiadas pelo Estado (aproximadamente 31 universidades) e universidades privadas de caráter confessional. O chamado setor privado era composto por aproximadamente 11 universidades de inspiração católica e uma universidade presbiteriana, a Mackenzie. Universidade particular era sinônimo de universidade confessional. Essas universidades, embora particulares, pela própria missão educacional das instituições religiosas, tinham certa preocupação com a qualidade do ensino e, em maior ou menor grau, ao longo dos anos, algumas delas enquadraram-se no modelo de universidade impulsionado pelo governo militar, voltado para a pesquisa e com programas de pós-graduação. Nesse período, a universidade ou era gratuita ou era paga, mas a instituição que cobrava pelos serviços educacionais não tinha nem poderia ter fins lucrativos.
O regime militar de 64 implantou uma política de modernização e reestruturação do sistema universitário impulsionada a partir da Lei no 5.540 de novembro de 1968, incluindo importantes bandeiras do movimento estudantil e de docentes das décadas de 50 e 60, tais como: a abolição da cátedra; a criação do departamento como unidade de ensino e pesquisa; a organização do currículo em duas etapas - a básica e a de formação profissionalizante; a adoção do sistema de crédito e da semestralidade; a institucionalização da pesquisa; etc. (Sampaio, 1998:44).

Além dessas medidas, a Reforma Universitária reconheceu no plano legal a autonomia didático-científica, disciplinar, administrativa e financeira da universidade, limitada, entretanto, pelo Ato Institucional no 5, de 13 de dezembro de 1968, e pelo Decreto-Lei no 477, de fevereiro de 1969. Sobre isso, Fávero (1998:198) afirma que, durante o regime militar, a gravidade do que acontecia em relação à universidade não estava expressa nos dispositivos legais, mas ocorria fora dessas normas: a universidade, como a sociedade, foi submetida a um regime de terror e de silêncio. A criação e a manutenção das Assessorias de Segurança dentro das universidades, a fim de impedir que mecanismos democráticos, mesmo quando previstos em lei, chegassem a ser efetivamente usados ou implementados, exemplificam muito bem essa realidade.

A reforma universitária optou no plano legal pelo fortalecimento das universidades ao decretar que o ensino superior deveria ser ministrado em universidades e excepcionalmente em estabelecimentos isolados. Apesar disso, esse dispositivo legal não foi respeitado e o Conselho Federal da Educação constantemente adotava medidas que possibilitavam a expansão do ensino privado por meio de estabelecimentos isolados. Deve-se lembrar que na década de 60 a pressão social por vagas no ensino universitário era muito grande, continuamente havia manifestações e mobilizações dos alunos que tinham conseguido entrar na universidade mas não estudavam, pois não havia vagas, os famosos "excedentes". Em 1960 eram aproximadamente 28.728 alunos excedentes; em 1968 - início da Reforma Universitária - esse número saltou para 125.414 alunos; em 1971 esse número chegou a 161.176 alunos. Como afirma Martins (1981:94), “o problema dos excedentes foi contornado através de uma avalanche de autorizações para abertura de novas escolas e ao mesmo tempo a permissão para as instituições já existentes aumentarem suas vagas sem atender a grandes exigências burocráticas".

Ao contrário dos demais países da América Latina, que diante da demanda de democratização do ensino acaba- 
ram massificando as universidades públicas, o regime militar optou pelo investimento financeiro na formação de uma universidade pública de elite, voltada para a pesquisa. Isso acarretou a implantação de programas de pósgraduação, a institucionalização da pesquisa acadêmica, a criação de estímulos para o desenvolvimento de pesquisas e obtenção de graus acadêmicos, e a manutenção de um número estável e restrito de alunos, impedindo desta forma a sua massificação. Paralelamente, optou por incentivar a criação de um sistema de ensino superior de massa que atendesse à elevada demanda social, por meio de uma rede de estabelecimentos isolados sob a iniciativa privada, dedicada basicamente à transmissão de conhecimentos em grande escala.

Os empresários da educação optaram por investir na criação de estabelecimentos isolados de pequeno porte $\mathrm{e}$ poucas foram as universidades mercantis criadas entre 1968 e finais dos anos 80 , as quais proliferaram somente no início da década de 90 . Para se ter uma noção da rápida expansão dessas instituições de ensino após o início da reforma de 68, pode-se dizer que em 1971 havia 463 estabelecimentos isolados, e entre 1971 e 1975 foram criados mais 162 instituições desse tipo.

Foram precisamente esses estabelecimentos isolados que posteriormente, na década de 80 , se transformaram em federação de escolas ou escolas integradas, e muitas delas adotaram o status de universidade. Convém mencionar que essas transformações estão vinculadas estritamente ao aumento de vantagens competitivas do mercado.

Aquelas universidades mercantis que em suas origens foram estabelecimentos isolados ou faculdades integradas já estavam desde aquela época, com o caráter de instituição mercantil enraizado. A respeito dessas instituições, Martins (1981:80) havia apontado que "a esmagadora maioria dessas instituições privadas que surgiram após o ano de 1968 se constituíram como empresas privadas capitalistas; ou seja, estavam voltadas para a procura de rentabilidade, utilizando a área educacional como um campo fértil para investimentos (...) com a finalidade de obtenção de lucro e de acumulação de capital".

Ao longo das décadas de 70 e 80 , quando da hegemonia das universidades públicas e das universidades confessionais, dificilmente se poderia falar da existência de um mercado de ensino universitário: existiam poucas universidades que o dinamizassem e possibilitassem o princípio da concorrência. Essa época pode ser considerada um período de mercado restrito ou de baixa concorrência. Se nos distanciarmos do mundo das universidades, podería- mos afirmar que no mesmo período existia um grande mercado de ensino superior composto pelos estabelecimentos isolados e faculdades integradas, havendo entre elas algumas diferenças. Embora existissem poucas instituições de elite, a maioria delas era composta por faculdades caracterizadas pela mera transmissão de conhecimentos e pela questionável qualidade, formando um mercado fértil, no qual concorriam instituições de ensino de segunda e terceira divisões.

Tomando como referência o Município de São Paulo, pode-se dizer que em termos de instituições de elite, até o final da década de 80 , os cidadãos paulistanos tinham poucas opções. Dentro da cidade podiam tentar estudar na PUC-SP, USP, ou Mackenzie. Entre os estabelecimentos isolados de elite de caráter público, existia a Escola Paulista de Medicina, e de caráter privado destacavam-se a Fundação Getúlio Vargas e a Escola Superior de Propaganda e Marketing. Fora do Município de São Paulo a opção era migrar para outras cidades e estudar nos campi da Unesp, Unicamp, UFSCar, Puccamp.

No âmbito do ensino de massa, existiam os estabelecimentos isolados, os mesmos que em sua maioria não eram valorizados pela elite acadêmica, pela mídia e pelas famílias de classes média e alta que possuíam uma história geracional de formação superior, devido à duvidosa qualidade de ensino que ofereciam, não possuindo nem status, nem prestígio, se comparadas com as universidades e os estabelecimentos isolados de elite citados. No entanto, diante da dificuldade de ingresso nas universidades, essas instituições tornaram-se opção de estudo superior para um número de alunos bastante elevado; por exemplo, a FMU tinha em 1977 aproximadamente 20 mil alunos, distribuídos em 16 prédios localizados na região sudeste, oeste, sul e centro da cidade de São Paulo; no vestibular de 1979 ofereceram 6.700 vagas, algumas centenas de vagas a mais se comparadas com as 6.240 vagas oferecidas pela USP.

Em municípios próximos de São Paulo foram criadas algumas universidades que, respeitando as regras do jogo (ensino gratuito ou pago, mas sem fins lucrativos), se autodenominavam entidades sem fins lucrativos, eram universidades que tiraram o monopólio confessional do ensino privado, tinham proprietários, eram de qualidade questionável se comparadas com as universidades de elite, não eram valorizadas pelas elites acadêmicas e sociais paulistanas, mas muito valorizadas em seus entornos territoriais. Elas surgiram para atender à grande demanda regional por ensino superior da população que o Estado 
não podia suprir, setores populacionais com recursos financeiros para pagar uma universidade, mas sem condições de conseguir uma vaga em universidades de elite, seja pela localização, seja pelas poucas e concorridas vagas oferecidas. Em outras palavras, eram as primeiras universidades mercantis criadas para conquistar uma fatia do mercado, liberando dessa forma pontos de tensão existentes em um sistema elitista que não conseguia atender às demandas de segmentos populacionais que almejavam ser incluídos no sistema universitário. Em 1973 foi criada a Universidade de Mogi das Cruzes, em 1985, a Universidade Brás Cubas e em 1986, a Universidade de Guarulhos. Foi na segunda metade da década de 80 que surgiu também uma nova universidade confessional católica, a Universidade São Francisco que recém começava a se expandir.

O surgimento dessas universidades ainda não tornava explícito o princípio da concorrência entre as universidades na cidade de São Paulo, pois as universidades de elite não encontravam concorrência, e não havia alteração na oferta de serviços porque as opções ainda eram reduzidas se comparadas com o acirramento da competitividade do mercado na década de 90.

As universidades mercantis ou, como alguns autores as chamam, novas universidades (Almeida, 1997) surgiram de forma marcante a partir do final da década de 80 . No Município de São Paulo foram criadas no espaço de nove anos, entre 1988 e 1997, dez universidades mercantis (Quadro 1) e uma universidade pública (a Escola Paulista de Medicina transformou-se na Universidade Federal de São Paulo).

\section{QUADRO 1}

Universidades Credenciadas ou Criadas

Município de São Paulo - 1988-1997

\begin{tabular}{lc}
\hline Universidades & Ano de Criação ou Credenciamento \\
\hline Paulista & 1988 \\
São Judas & 1989 \\
Camilo Castelo Branco & 1989 \\
Ibirapuera & 1992 \\
Cidade de São Paulo & 1992 \\
Cruzeiro do Sul & 1993 \\
Bandeirante & 1993 \\
São Marcos & 1994 \\
Santo Amaro & 1994 \\
Anhembi Morumbi & 1997
\end{tabular}

Fonte: Almeida (1997).
Se considerarmos que até 1988 existiam em São Paulo somente quatro universidades (uma universidade pública - USP -, e três confessionais comunitárias - PUC-SP, Mackenzie e a nova Universidade São Francisco), até 1997 houve um crescimento de $250 \%$ (Gráfico 1), totalizando 15 universidades.

Em 2000, existe o total de dez universidades mercantis e cinco centros universitários, com o mesmo caráter mercantil desse modelo de universidade emergente (Uninove, Unibero, Uni Sant'Anna, UNI-FMU, São Camilo). Em termos de opções de ensino universitário, considerando os centros universitários, que para concorrer no mercado de ensino superior apresentam-se ao consumidor com a palavra UNI antecedendo seus nomes para ressaltar seu caráter universitário, pode-se afirmar que em 2000 a oferta de ensino universitário foi ampliada de tal forma que ele está sendo oferecido por 20 instituições universitárias: duas universidades públicas, três universidades confessionais e 15 instituições mercantis (dez universidades e cinco centros universitários).

Obviamente, a situação do Município de São Paulo é reflexo do que vem acontecendo no Brasil. Se no início da Reforma Universitária de 68 o ensino privado era dominado por 11 universidades católicas e uma presbiteriana, até 1985 existiam 20 universidades particulares em todo o Brasil. O crescimento expressivo deu-se de 1985 a 1990, e nesse período de cinco anos houve um crescimento de $100 \%$, com a criação de mais 20 universidades particulares. Entre 1990 e 1998 foram criadas mais 36 universidades particulares, ou seja, entre 1985 e 1998 havia o total
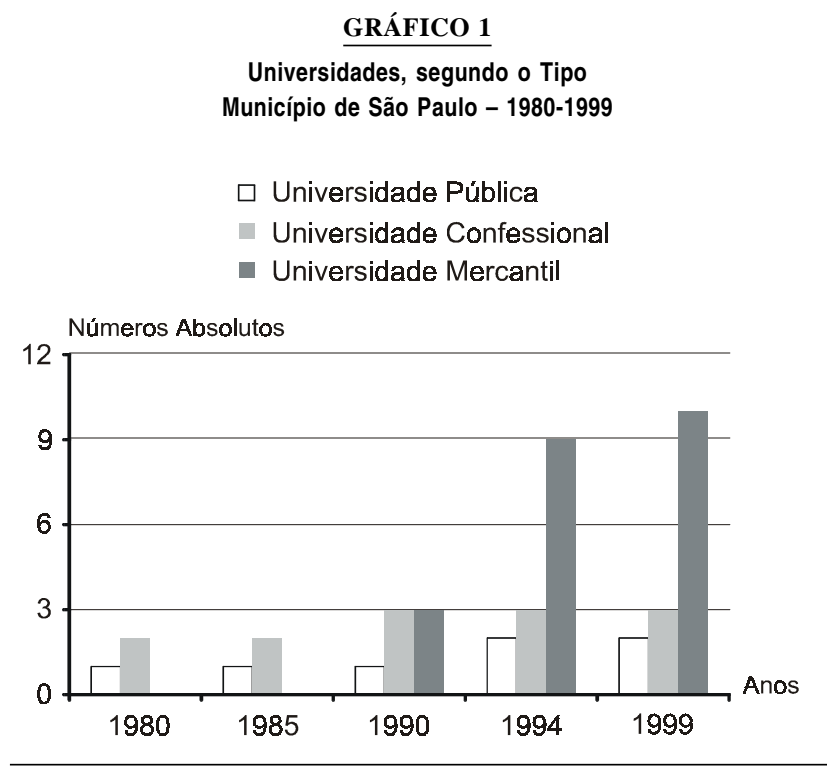

Fonte: Almeida (1997). 
de 56 universidades privadas, um salto quantitativo de $280 \%$.

Se antes, somente existiam três universidades para toda a cidade de São Paulo, concentradas na região CentroOeste, em 2000 existem 15 universidades para uma metrópole de 10 milhões de habitantes espalhadas em todas as regiões da cidade. Formaram-se mercados regionais: as universidades concorrem pelos clientes em potencial na Zona Leste, na Zona Norte, no Centro e na Zona Sul. Essa descentralização geográfica facilitou o acesso às universidades, reduzindo o tempo de locomoção, fator importante em uma cidade caracterizada pelas grandes distâncias, quilômetros de trânsito e congestionamento. Uma pesquisa recente registra que a localização da universidade é um fator fundamental, quase determinante, no momento em que o aluno tem de optar por estudar em uma universidade: dos 250 alunos pesquisados da Universidade Ibirapuera, $87 \%$ responderam que estudam nessa instituição pela sua boa localização, porque é próxima do trabalho ou de casa; dos 377 alunos pesquisados da Universidade Cruzeiro do Sul, $83 \%$ a escolheram pelo mesmo motivo. Os índices também se mantêm altos em outras universidades: na Unicastelo, $73 \%$ dos alunos pesquisados apontaram a localização; na Unicid, $65 \%$; na Uniban, 68\%, na Universidade São Judas, 58\% (Jardilino e Santos, 1999).

\section{A INSTITUCIONALIZAÇÃO DO PRINCÍPIO DA CONCORRÊNCIA}

Sem dúvida alguma, um dos motivos principais que determinaram o surgimento das novas universidades foi o estabelecimento das "vantagens competitivas" pela Constituição de 1988, posteriormente regulamentado pela LDB - Lei de Diretrizes e Bases da Educação de 1996, concedido à instituição universidade por meio do princípio da autonomia didático-científica, através do qual não precisariam mais se submeter aos entraves burocráticos do extinto Conselho Federal da Educação, seja para a abertura de determinados cursos, seja para a ampliação ou redução do número de vagas para atender à demanda. A legislação estabelece autonomia para as universidades criarem, organizarem ou extinguirem, em suas sedes, cursos e programas de educação superior previstos na lei, contemplando algumas exceções. ${ }^{1}$ As universidades também poderiam fixar o número de vagas a serem oferecidas ao mercado de acordo com a capacidade institucional, podendo ampliar e diminuir vagas dentro de seus recursos orçamentários disponíveis. Como aponta Sampaio (1998:67), tudo isso "na prática significa fechar cursos menos procurados, abrir outros com maior capacidade de atrair clientela, alterar o número de vagas oferecidas de acordo com as oscilações das matrículas e da evasão, entre outras providências; decisões como essas de ajuste ao mercado podem ser implementadas sem serem submetidas à tramitação burocrática pela qual passam os pleitos de autorização de cursos encaminhados pelas instituições não-universitárias".

Com a chegada das universidades mercantis, pode-se afirmar que se institucionalizou o mercado de ensino universitário. Antes do surgimento em massa dessas universidades, no Município de São Paulo existiam apenas três universidades que atendiam à demanda por ensino superior em universidades. Após a constituição de 1988 até a segunda metade da década de 90 constatou-se o surgimento de dez universidades, as mesmas que ao competir entre elas estabeleceram o princípio da concorrência. A institucionalização desse mercado na década de 90 deuse de forma acelerada e num curto espaço de tempo, revelando uma concorrência extremamente acirrada, descrita por alguns autores como caso de "verdadeiro canibalismo explícito", no qual cada universidade mercantil tentava ganhar mais espaço e conquistar uma fatia maior do mercado, valendo-se para isso de todos os recursos disponíveis na área de publicidade e marketing. Para se ter uma dimensão da importância da publicidade, um levantamento feito em 1998 mostrou que entre os 15 maiores anunciantes de outdoor encontravam-se cinco instituições de ensino privadas.

O acirramento da competição no mercado de ensino universitário, na primeira metade da década de 90 , revelou a profissionalização e a agressividade das propagandas utilizadas pelas universidades mercantis para conquistar o consumidor. Poderia-se dizer que, em termos de propaganda, a diferença entre o produto oferecido por essas universidades e qualquer outro produto direcionado para o público jovem era quase inexistente.

Em contraste à década de 80 - período em que também havia propagandas, mas sem haver profissionalização, mercantilização e agressividade decorrente da acirrada concorrência -, a década de 90 apresentou uma guerra pelo consumidor, na qual, longe de mostrar compromisso com a excelência acadêmica, as universidades utilizaram-se de estratégias de sedução do cliente em potencial: os jovens egressos do segundo grau. Assim, criaram-se grandes campanhas veiculadas pe- 
los principais meios de comunicação, com artistas de $\mathrm{TV}$, modelos jovens dentro de um mundo de ilusão, mostrando que estudar em uma universidade não é uma coisa chata, pelo contrário, é prazerosa e divertida, como estar em um clube de férias (Sampaio, 1998). No final da década de 90, a agressividade se deu também no preenchimento das vagas remanescentes dos vestibulares, com descontos nas matrículas e nas anuidades caso os alunos deixassem outras universidades e decidissem se matricular na instituição que estava fazendo a promoção. Diante do excesso de vagas ofertadas no mercado e não-preenchidas, as universidades faziam, após o vestibular, o número de chamadas necessário para preenchê-las, bem como faziam mais de um vestibular para um mesmo semestre.

Considerando as diferenças entre universidades, Almeida (1997) assinala que as universidades históricas e tradicionais geralmente restringem suas estratégias de marketing ao que Theodore Levitt (1985) chama de produto genérico, isto é, ao produto em si: os cursos que estão sendo oferecidos ao mercado. Já essas novas universidades, na sua estratégia mercadológica, tendem a mostrar outros elementos ou qualidades distantes do produto em si, os mesmos que muitas vezes ganham maior destaque que o principal produto oferecido pela universidade: $\mathrm{o}$ próprio curso. São aspectos que procuram seduzir o consumidor e tornar atraente o produto genérico. Almeida (1997) aponta que, na guerra pelo consumidor, uma piscina, uma sala de musculação, uma localização próxima do metrô, um salão de beleza, uma sala de informática, convênios com "grandes" empresas, uma escola de motorista, um instituto de idiomas, uma praça de alimentação, são elementos que ganham ênfase, muitas vezes maior que o curso ofertado pela universidade. Nesse sentido, as universidades mercantis acabam enfatizando outros aspectos que Levitt chama de produtos esperados pelo cliente (engana-se quem acredita que todo cliente procura somente ensino de qualidade), produtos aumentados (estratégias que ampliam o produto além do que é solicitado ou esperado pelo cliente), produtos potenciais (o que se pode acrescentar de novo ao produto).

A guerra entre universidades explicitada na primeira metade da década de 90 ganhou novos contornos após determinadas exigências legais ocorridas com a LDB, especificamente com a Portaria oㅡ 971 de 22 de agosto de 1997, que determinou que as universidades deveriam tornar públicas, através de catálogo a ser enviado à Secretaria de Educação Superior do MEC - Ministério de Edu- cação e do Desporto, as condições de oferta de cursos, fazendo constar uma longa e minuciosa lista de informações sobre os dirigentes da universidade e os coordenadores dos cursos, os valores das mensalidades, a infraestrutura, os resultados das avaliações do MEC, etc. ${ }^{2}$

Sampaio (1998:353) registra três mudanças significativas na propaganda escrita, a partir da introdução dessas exigências legais:

- as duas folhas dobradas típicas de folders, passaram a ser 20 ou 30 páginas, organizadas e diagramadas como revistas;

- as atividades escolares e as instalações físicas passaram a ser o foco das atividades, os alunos estudando ou usando a infra-estrutura acadêmica tornaram-se coadjuvantes dessas instalações;

- os catálogos dão a impressão de não se destinarem ao vestibulando, mas ao MEC.

Essa interferência legal possibilitou que as estratégias de marketing e publicidade deixassem de enfocar os produtos ofertados pelas universidades mercantis como mais uma mercadoria para o público jovem, bem como revelou o surgimento de um Estado preocupado com a garantia de informações minimamente necessárias para que o consumidor tenha maiores condições de discernir sobre a escolha do produto que se encaixe em suas necessidades e condições financeiras.

Com a institucionalização do princípio da concorrência, constata-se a passagem de um "mercado de demanda" para uma estrutura mais seletiva de "mercado de oferta" (Calleja, 1990). Com o monopólio da PUC-SP e Mackenzie no campo universitário privado, no Município de São Paulo, predominava o mercado de demanda, para o qual qualquer produto oferecido por essas universidades encontrava um número elevado de consumidores, pois havia uma grande demanda por produtos dessas instituições. Naquela época, se essas universidades houvessem ampliado a oferta de cursos por meio da criação de uma estrutura multicampi, sem dúvida alguma teriam obtido facilmente consumidores para seus produtos e, com isto, gerado lucros que teriam sido utilizados de acordo com suas diretrizes institucionais. Com o elevado número de universidades, assiste-se ao surgimento de um "mercado de oferta", no qual deve-se produzir o que o mercado exige - exigências que podem ser reais ou fictícias - e, principalmente, o que os consumidores querem, dentro de um contexto de acirrada concorrência por clientes em potencial e, principalmente, de excesso de produtos para um número de consumidores que, embora crescente, não con- 
some todas as vagas e serviços oferecidos pelas universidades particulares no Estado de São Paulo. Assim o "mercado de oferta" é resultado da junção de vários elementos: de um cenário de grande concorrência, do excesso de produtos em relação ao número de consumidores em potencial e das novas exigências do mercado, predominantemente voltado para a prestação de serviços.

\section{CONCORRÊNCIA, DIVERSIFICAÇÃO E DIFERENCIAÇÃO}

No panorama nacional constatou-se, nos últimos anos, uma certa estagnação do número de matrículas nas IES Instituições de Ensino Superior privadas (englobando-se universidades, federações de escolas, faculdades integradas e estabelecimentos isolados), com um ligeiro crescimento em 1998 (Schwartzman, 1999), enquanto no Estado de São Paulo o mercado apresentou uma demanda que crescentemente veio sendo atendida pelas universidades particulares. Em 1995 as IES privadas representavam 75,9\% do total das matrículas do Estado, crescendo para 77,7\% em 1996, 79,1\%, em 1997, chegando a 80,6\%, em 1998.

Se por um lado o número de matrículas aumentou, por outro se deve destacar que, em 1998, 14,4\% das vagas oferecidas não foram preenchidas. Isso quer dizer que existiam 12.341 vagas à disposição dos consumidores. A necessidade de preencher essas vagas foi um dos motivos que contribuiu para a acirrada competição no mercado de ensino universitário.

A institucionalização do mercado deixa explícita uma diversificação de produtos e serviços educacionais sem precedentes, bem como uma acentuada diferenciação entre as universidades que interagem no mercado de ensino. É precisamente essa grande diversificação de produtos e serviços,colocados no mercado por universidades com os mais variados perfis e missões institucionais, que caracteriza o chamado "mercado de oferta" em contraposição ao "mercado de demanda".

Deixando de lado a USP que possui financiamento estatal, a PUC-SP e a Universidade Mackenzie são instituições tradicionais vinculadas à qualidade de ensino e excelência acadêmica, seja na graduação, como no Mackenzie, ou graduação e pós-graduação, como na PUC-SP, as mesmas que dentro da cidade de São Paulo podem ser consideradas top-universidades, caracterizando-se por possuírem prestígio obtido em tempos de mercado restrito ou de baixa concorrência. Nesse novo cenário de acirrada concorrência, as top-universidades vêm adaptando-se aos novos tempos, pois elas, tanto quanto as universidades mercantis, também dependem das mensalidades pagas pelos alunos para garantir seus financiamentos. Como assinalam Tachizawa e Andrade (1999:22), nessa nova era de competição nenhuma universidade pode se sentir "excessivamente confiante com as fatias de mercado e as posições competitivas conquistadas (...). Com mercados e seus protagonistas em constante modificação, a possibilidade de que as IESs possam estabelecer vantagem competitiva duradoura não existe mais. Nenhuma instituição de ensino superior, enfim, pode se dar ao luxo de descansar sobre seus louros; cada qual tem de inovar incessantemente para poder competir e sobreviver".

$\mathrm{O}$ "mercado de oferta" exige que as top-universidades, além de profissionalizar as propagandas publicitárias, estejam atentas às novas demandas do mercado, oferecendo novos produtos e aprimorando aqueles que já oferecem. No caso da PUC-SP, verificou-se em 1999 o oferecimento de novos cursos no âmbito da graduação, como Turismo, Comunicação e Artes do Corpo, Tecnologias de Mídias Digitais e Comunicação em Multimeios. Aliás, o curso de Turismo geralmente tem sido considerado como um curso técnico e sobre ele sempre recai um olhar de menosprezo acadêmico.

O aprimoramento permanente dos produtos é uma decorrência não somente da competição do mercado, mas também do surgimento de uma série de medidas governamentais que estabelecem parâmetros para medir a qualidade dos produtos oferecidos pelas universidades, os mesmos que podem ser considerados instrumentos de auxílio ao consumidor no momento da escolha dos produtos universitários. No mercado do ensino universitário não há espaço para instituições que queiram se valer da fama conquistada com a boa "imagem de marca"; mecanismos de avaliação de cursos, tais como o Exame Nacional de Cursos e a avaliação anual das condições de oferta (contemplando três itens: qualificação dos professores, organização didático-pedagógica e instalações da faculdade), impulsionados pelo Estado, obrigam as universidades de excelência a rever constantemente seus produtos. Isso pode ser exemplificado com o que aconteceu após a divulgação da avaliação do MEC de cursos superiores correspondentes aos anos 1998 e 1999. Em 1999, o MEC apresentou uma lista com 101 cursos de graduação que teriam de ser reavaliados ou corriam o risco de perder a autorização para funcionar. Nessa lista estava incluído o curso de Direito da Universidade Mackenzie - os alunos tiveram muito bom desempenho no provão de 1996, 1997 e 1998, ao obterem letra A, B, A, respectivamente - devido aos itens 
instalações e organização didático-pedagógica, considerados insuficientes. Em 2000, o MEC divulgou uma lista de 94 universidades com o risco de perder o credenciamento, incluindo o curso de Jornalismo da PUC, cuja qualificação docente e de infra-estrutura foram avaliadas como insuficientes. Em ambos os casos as reitorias, coordenadores, professores e alunos se posicionaram e questionaram os métodos utilizados pelo MEC. No caso da Universidade Mackenzie, os próprios alunos, que na época se mobilizaram contra a atitude do MEC, declararam na imprensa a ocorrência de mudança e melhorias no curso. No caso da PUC, o fato ainda é muito recente para se verificar as mudanças que provavelmente virão no curso de Jornalismo.

"Admite-se que os estatutos eram freqüentemente malaplicados; os programas, estudados de maneira incompleta; as durações obrigatórias dos estudos, não respeitadas, mesmo os exames algumas vezes eram fraudados; negligência e fraude grassavam amplamente (...) O acesso rápido e a baixo custo do diploma constituía o objetivo confesso de muitos estudantes" (Charle e Verger, 1996:29).

Se afirmássemos que o texto acima foi extraído de uma pesquisa sobre as universidades paulistas da década de 80 , imediatamente o leitor se lembraria das universidades que tinham fama de comercializar títulos, de formar bacharéis com vistas grossas em relação à sua frequiência às aulas. Pois bem, o texto acima foi retirado de um livro no qual se descreve a situação de muitas universidades provincianas no final da Idade Média. O seguinte texto pode ser ainda mais elucidativo: “....a partir do século XVII (...) Na França, se as principais universidades - Paris, Toulouse ou Montpellier - preservavam um determinado nível de exigência, pequenas universidades provincianas - Avignon, Orange, Orléans, Nantes, Caen, Reims - especializaram-se vergonhosamente na venda de graus a preços de liquidação e sem exame sério. A fraude revestia-se de múltiplas formas: teses redigidas por autores profissionais, envio de substituto em lugar do verdadeiro candidato, inscrições prévias feitas por correspondência, etc. É impossível avaliar a importância dessas práticas, mas elas eram amplamente difundidas..." (Charle e Verger, 1996:60).

Os textos citados mostram que a diferenciação entre as universidades sempre fez parte dos sistemas universitários. No Brasil, sempre houve uma profunda diferenciação em diversos momentos da sua história. Com a entrada em cena das universidades mercantis, na década de 90, as diferenciações entre instituições podem ser constatadas a partir de diversas variáveis, como qualidade, missão, preço, localização, etc.
Por sua vez, a existência de mecanismos públicos de avaliação possibilita também a hierarquização das universidades, pois existem indicadores que permitem colocar as universidades em uma hierarquia a partir de critérios de avaliação de qualidade instituídos pelo Estado. As universidades tradicionais terão de esforçar-se para justificar a fama e o prestígio adquiridos em tempos de mercado restrito; por sua vez, as universidades mercantis poderão se diferenciar, ganhando destaque no nicho de mercado escolhido.

Eunice Durham e Helena Sampaio (1996), utilizando os trabalhos de Geiger (1986), afirmam que "la educación superior privada en Brasil se encuadraría dentro de lo que el define como mass private sector, que cumplen esencialmente el papel de acomodar el grueso de la demanda popular por educación superior". Sob essa perspectiva, o mass private sector, se caracterizaria por:

- complementar os setores públicos que são relativamente pequenos, mais seletivos e fortemente voltados para as carreiras de elite;

- rápido poder de expansão mobilizando recursos privados, com o propósito de absorver e adaptar-se à demanda;

- atender à demanda em grande escala, de forma rentável, comprometendo a qualidade dos produtos.

Diante da grande diversificação institucional que vem ocorrendo no mercado de ensino universitário, pode-se afirmar que a categoria universidade mercantil é muito mais ampla e rica do que as restrições do mass private sector. Deve-se ter claro que, no Brasil, as universidades mercantis nasceram para atender às demandas de massa, mas isso não significa que não possam existir universidades mercantis que sejam centros de excelência, como existem em outros países, onde a maioria desses centros está vinculada à iniciativa privada. Nesse sentido, é fundamental distinguir as universidades mercantis de massa e as universidades mercantis de elite.

Sem dúvida alguma, as universidades mercantis surgiram no Brasil como parte do mass private sector, na esteira do ensino público voltado para o ensino de elite. ${ }^{3}$ Embora seja difícil desvincular as universidades mercantis do mass private sector e de um ensino de qualidade questionável, o surgimento de universidades mercantis de elite é uma possibilidade aberta. A questão é definir sua missão e investir e competir dentro do nicho de mercado escolhido. A emergência de instituições mercantis com qualidade está começando a surgir ou a se expandir, como exemplo pode-se citar a Ibmec, faculdade com $60 \%$ de 
docentes com o título de doutor, comandada pelos ex-banqueiros Paulo Guedes, do ex-Pactual, e Claudio Haddad, do Banco Garantia. Esse último declarou à imprensa acreditar que a educação privada pode dar dinheiro e oferecer qualidade. Na mesma perspectiva, cita-se a nova Faculdade Trevisan, resultado da sociedade entre o empresário Antoninho Trevisan e o Banco Fator, que planeja investir 18 milhões de reais nos próximos quatro anos. Nela os alunos trabalham com laptops fornecidos pela faculdade (Folha de S.Paulo, 28/12/98).

\section{A LÓGICA EMPRESARIAL EM QUESTÃO}

As universidades mercantis caracterizam-se pela predominância da lógica empresarial, da procura do lucro. Falamos de negócios e, sob essa perspectiva, as universidades mercantis investem onde percebem que há demanda e, portanto, podem obter lucro. Se tomarmos como referência o Brasil, verifica-se que $84,2 \%$ do total de universidades particulares estão localizadas na região Sudeste e Sul, enquanto $18 \%$ estão distribuídas entre a região Norte (uma universidade), Nordeste (seis universidades) e Centro-Oeste (cinco universidades). Somente no Estado de São Paulo encontramos 30 universidades particulares.

Além do investimento em regiões onde há demanda com poder aquisitivo para adquirir produtos educacionais, verifica-se que se dá prioridade aos cursos que apresentam grande demanda e baixo custo de investimento financeiro. No Estado de São Paulo, em 1998, os cinco primeiros cursos em número de alunos matriculados em universidades particulares são aqueles que implicam baixo investimento. Em primeiro lugar está o curso de Direito com 73.580 alunos matriculados; em segundo, por Administração com 44.343 alunos; em terceiro lugar, Engenharia com 24.565 alunos; em quarto lugar, Comunicação Social com 19.769 alunos; e em quinto, Psicologia com 15.719 alunos.

Como já foi registrado, as universidades mercantis voltadas para o ensino de massa apresentam como característica a procura do lucro nos nichos de competitividade escolhidos. Em decorrência disso, pode-se verificar a implantação de ações voltadas para a redução dos, digamos, custos de produção, o que certamente influi na qualidade do produto ofertado. Aliás, a questão da má qualidade dos produtos oferecidos pelas universidades mercantis de massa tem sido talvez um dos pontos consensuais entre analistas e pesquisadores do ensino superior.

Dados oficiais revelam que a maioria das universidades mercantis de massa contrata professores pelo regime de trabalho hora/aula. Se o objetivo é reduzir custos, sem dúvida alguma o pagamento hora/aula é o mais indicado, pois o professor recebe pela aula ministrada, mas esse sistema, sem dúvida, é o pior que existe, uma vez que o professor somente se interessa em chegar na sala de aula e ir embora, não havendo a possibilidade de ficar auxiliando

TABELA 1

Regime de Trabalho dos Professores das Universidades Criadas após 1988

Município São Paulo - 1998

\begin{tabular}{|c|c|c|c|c|c|c|c|c|}
\hline \multirow{3}{*}{$\begin{array}{l}\text { Universidades Mercantis } \\
\text { de Massa }\end{array}$} & \multicolumn{8}{|c|}{ Regime de Trabalho dos Professores } \\
\hline & \multicolumn{2}{|c|}{ Horista } & \multicolumn{2}{|c|}{ Tempo Parcial } & \multicolumn{2}{|c|}{ Tempo Integral } & \multicolumn{2}{|c|}{ Total } \\
\hline & №s Absolutos & $\%$ & №s Absolutos & $\%$ & №s Absolutos & $\%$ & №s Absolutos & $\%$ \\
\hline Paulista & 561 & 41,2 & 533 & 39,1 & 269 & 19,7 & 1.363 & 100,0 \\
\hline São Judas & 485 & 72,6 & 175 & 26,2 & 8 & 1,2 & 668 & 100,0 \\
\hline Camilo Castelo Branco & 471 & 75,1 & 109 & 17,4 & 47 & 7,5 & 627 & 100,0 \\
\hline Ibirapuera & 367 & 73,5 & 114 & 22,9 & 18 & 3,60 & 499 & 100,0 \\
\hline Cidade de São Paulo & 361 & 61,8 & 169 & 28,9 & 54 & 9,3 & 584 & 100,0 \\
\hline Cruzeiro do Sul & 267 & 59,4 & 132 & 29,3 & 51 & 11,3 & 450 & 100,0 \\
\hline Bandeirante & 382 & 55,1 & 92 & 13,3 & 219 & 31,6 & 693 & 100,0 \\
\hline São Marcos & 235 & 73,4 & 56 & 17,5 & 29 & 9,1 & 320 & 100,0 \\
\hline Santo Amaro & 404 & 62,9 & 198 & 30,9 & 40 & 6,2 & 642 & 100,0 \\
\hline Anhembi Morumbi & 288 & 75,4 & 65 & 17,0 & 29 & 7,6 & 382 & 100,0 \\
\hline
\end{tabular}

Fonte: MEC/Inep/Seec. 
o aluno após a aula ou ficar mais 15 minutos fora dela esclarecendo dúvidas e respondendo questões que os alunos trazem de casa. Essas atividades fundamentais estão fora de cogitação. O professor não é estimulado pela universidade e, portanto, ela não pode exigir maiores compromissos, nem apelar para a função social do docente, pois o professor precisa trabalhar em duas, três, quatro ou mais universidades para garantir um salário no mínimo decente. Esse sistema, além de não criar vínculos entre a universidade e o professor, nem criar a possibilidade da existência de um espírito de comunidade universitária, faz que com que a universidade se torne um espaço de produção "fordista" de diplomas.

Se tomarmos como referência os dados existentes em 1998 (Tabela 1), pode se constatar que metade das universidades mercantis paulistanas mantém um índice muito elevado do seu corpo docente sob o regime horista, acima de $70 \%$, e duas delas mantêm mais de $60 \%$ de seu corpo docente sob esse mesmo regime de trabalho.

Aos dados citados deve-se ainda acrescentar um outro problema: o grau de titulação do corpo docente. Sem dúvida, contratar professores com baixa titulação é uma forma de reduzir custos. No entanto, deve-se considerar que em alguns casos se dá mais importância à experiência profissional do professor para a formação do aluno, do que ao título de mestre ou doutor, e existem profissões e regiões do país que dificilmente possuem mestres e douto- res no mercado. Resta a dúvida, será que há reserva de mestres e doutores suficiente para atender à grande demanda do mercado universitário? Embora polêmico, o grau de formação constitui-se em um indicador da qualidade do corpo docente, como apontam Silva Jr. e Sguissardi (1999:52), e os resultados do provão "demonstraram inquestionavelmente que o conceito A está diretamente relacionado a IES que possuem alto percentual (mais de 50\%) de seu corpo docente com titulação de mestrado e doutorado e o mesmo percentual de docentes contratados em regime de trabalho superior a 20 horas semanais".

Em 1995, do total de professores das universidades privadas citadas, $61,8 \%$ tinham apenas o título de bacharel ou de especialista; $38,2 \%$ eram mestres ou doutores. Os dados de 1998 revelam um pequeno aumento do número de mestres e doutores para $42 \%$. O número de professores que têm somente graduação ou o título de especialista ainda é elevado, $58 \%$.

Os percentuais variam de universidade para universidade, mas, em linhas gerais, pode-se dizer que essas universidades procuram ficar no limite exigido pelo Estado para manter o status de universidade, isto é, um terço do corpo docente com titulação de mestre ou doutor. Os elevados índices de professores bacharéis ou especialistas levam a concluir que os gastos com mão-de-obra mais especializada ou com investimento em programas de quali-

TABELA 2

Conceito no Provão e Ano em que os Cursos Foram Avaliados pela Primeira Vez nas Universidades Criadas após 1988 Município de São Paulo - 1998

\begin{tabular}{|c|c|c|c|c|c|c|c|c|c|c|}
\hline \multirow{3}{*}{$\begin{array}{l}\text { Universidades Mercantis } \\
\text { de Massa }\end{array}$} & \multicolumn{10}{|c|}{ Curso/Conceito e Ano de Avaliação } \\
\hline & \multirow[t]{2}{*}{ Administração } & \multirow[t]{2}{*}{ Comunicação } & \multirow[t]{2}{*}{ Direito } & \multirow[t]{2}{*}{ Letras } & \multicolumn{3}{|c|}{ Engenharia } & \multirow[t]{2}{*}{ Odontologia } & \multirow[t]{2}{*}{ Matemática } & \multirow[t]{2}{*}{ Veterinária } \\
\hline & & & & & Civil & Química & Elétrica & & & \\
\hline Paulista & C - 1996 & & C - 1996 & B - 1998 & C- 1996 & D - 1997 & D - 1998 & C - 1997 & B - 1998 & B - 1997 \\
\hline São Judas & B - 1996 & C - 1998 & B - 1996 & A - 1998 & B - 1996 & & B - 1998 & & A - 1998 & \\
\hline Camilo Castelo Branco & C - 1996 & & C - 1996 & D - 1998 & C - 1996 & C - 1997 & & E - 1997 & C - 1998 & \\
\hline Ibirapuera & D - 1996 & & C - 1997 & C - 1998 & & & & & C - 1998 & \\
\hline Cidade de São Paulo & C - 1996 & & C - 1997 & C - 1998 & & & & D - 1997 & & \\
\hline Cruzeiro do Sul & D - 1996 & & C - 1998 & C - 1998 & & & & & C - 1998 & \\
\hline Bandeirante & D - 1998 & C - 1998 & E - 1998 & C- 1998 & & & & & & \\
\hline São Marcos & C - 1996 & & & C- 1998 & & & & & C - 1998 & \\
\hline Santo Amaro & C - 1998 & & & B - 1998 & & & & D - 1997 & C - 1998 & \\
\hline Anhembi Morumbi & C - 1996 & & & C- 1998 & & & & & B - 1998 & \\
\hline
\end{tabular}

Fonte: MEC/Inep/Exame Nacional de Cursos. 
ficação docente, bem como com encargos sociais/trabalhistas, são elementos que pesam no momento de optar pela ampliação do quadro de docentes titulados, tudo isso, é claro, para reduzir os "custos de produção" e maximizar os lucros.

Em relação à qualidade dos cursos, até a instauração do Exame Nacional de Cursos, em 1996, não existiam indicadores sobre a qualidade dos cursos oferecidos pelas universidades mercantis de massa, o único conhecido, que se generalizava, era que os cursos das universidades mercantis eram ruins ou de qualidade muito questionável.

Se forem considerados os conceitos obtidos na primeira avaliação realizada nos cursos das dez universidades analisadas, pode-se constatar a frágil formação recebida pelos alunos que estudam nessas universidades, corroborando-se a idéia generalizada da má qualidade dessas universidades. Poucas se destacaram em algum curso específico. Em geral, os resultados foram reflexo da precária qualidade dos cursos oferecidos. Dos 49 cursos avaliados, $57,1 \%$ obtiveram letra C (28 cursos), 18,4\%, letra D (nove cursos), 4,1\%, letra E (dois cursos). Somente $4,1 \%$, equivalente a dois cursos, obtiveram letra $\mathrm{A}$, e $16,3 \%$, equivalente a oito cursos, obtiveram letra B. Dentre as dez universidades, somente uma delas, a Universidade São Judas, teve um desempenho bastante positivo: dos sete cursos avaliados somente um curso obteve letra $\mathrm{C}$, quatro cursos, letra B, e dois cursos, letra A.

\section{OBSERVAÇÕES FINAIS}

A institucionalização do mercado é uma realidade no cenário universitário que não pode ser ignorada. Os contextos mudaram e para analisar as universidades brasileiras deve-se considerar não somente o mercado universitário como elemento impulsionador de mudanças, mas também a passagem de um cenário marcado pelo mercado restrito ou de baixa concorrência, que sustentaria o mercado de demanda, para um mercado pautado pela acirrada concorrência, propiciando o surgimento do mercado de oferta.

A concorrência entre universidades pela ampliação e conquista de novos mercados chegou a tal magnitude que no início de 2000 colocou em crise o Conselho Nacional da Educação - o mesmo que surgiu como alternativa ao tão mal-falado e desgastado Conselho Federal da Educação - que se viu envolvido em sérias acusações de irregularidades. Atrás de todo esse escândalo, existe a pugna de interesses financeiros, interes- ses de mercado. Duas grandes universidades mercantis paulistanas, a Unip e Uniban, estão se enfrentando em diversas arenas de luta: no plano legal e no confronto direto pelos clientes-consumidores de produtos educacionais, oferecendo promoções aos que adquirem seus produtos. Uma amostra disso é a propaganda da Uniban, amplamente veiculada na imprensa paulistana, na qual os universitários de $2^{\circ}$ e 3 ㅇ anos de Osasco, Alphaville e Barueri que se transferirem para a Uniban, terão $50 \%$ de desconto na anuidade. O pagamento efetuado em outra instituição (leia-se na Unip) será integralmente descontado da anuidade na Uniban. Basta apresentar o comprovante de matrícula.

Apesar das sérias críticas que podem ser feitas, as universidades mercantis de massa possuem o grande mérito de atender à demanda por ensino superior que o Estado não consegue prover. O princípio de ensino universal público e gratuito constitui-se em uma importante bandeira que não conseguiu se concretizar na realidade. Sem dúvida alguma, ouvir uma afirmação categórica como "as universidades mercantis estão democratizando o acesso ao ensino superior" deve ser frustrante para todos aqueles que sonhavam que algum dia esta democratização ocorresse pela ampliação do serviço educativo público e gratuito fornecido pelo Estado. No entanto, a realidade é outra: foram as universidades mercantis que possibilitaram a democratização do ensino superior e foi a partir da presença delas que um maior número de pessoas pôde ter acesso a uma universidade.

A questão da qualidade de ensino é muito séria e delicada e a intervenção do Estado é necessária, mas deve ser redimensionada, não devendo limitar e coibir a iniciativa dos empresários na área do ensino superior, mas principalmente garantir espaços e instrumentos que possibilitem a defesa dos direitos dos cidadãos-consumidores. Nesse sentido, os mecanismos de avaliação de qualidade, principalmente sua ampla divulgação e publicização, podem contribuir para a construção de uma sociedade de consumidores conscientes e responsáveis. Em tempos de "mercados de oferta", existe uma grande diversidade de produtos dirigidos para clientes com os mais variados perfis, e o importante é os consumidores escolherem conscientemente os produtos e serviços que irão adquirir, avaliando qualidade, expectativas individuais e condições financeiras.

Finalizando, acredita-se que a esfera do mercado e do consumo de bens educacionais possibilita a percepção de novos espaços do exercício da cidadania. Como afirma Canclini (1995:57) o processo de consumo está sendo visto como algo 
mais complexo do que uma simples relação entre meios manipuladores e uma massa de consumidores dóceis. Nesse sentido, "cuando se reconoce que al consumir también se piensa, se elige y reelabora el sentido social hay que analizar cómo interviene esta área de apropriación de bienes y signos en formas más activas de participación que las que habitualmente se ubican bajo el rótulo de consumo. En outros términos, debemos preguntarnos si al consumir no estamos haciendo algo que sustenta, nutre y hasta cierto punto constituye un nuevo modo de ser ciudadanos" (1995:43).

\section{NOTAS}

E-mail do autor: aicf1@uol.com.br

1. Cursos como Medicina, Odontologia e Psicologia deverão ser submetidos à prévia avaliação do Conselho Nacional de Saúde, o curso de Direito dependerá de prévia manifestação do Conselho Federal da Ordem dos Advogados do Brasil.

2. Entre as principais informações que devem constar no catálogo pode-se destacar: relação dos dirigentes, coordenadores de cursos e programas, indicando titulação e/ou qualificação profissional e regime de trabalho; relação nominal do corpo docente da instituição, indicando titulação, qualificação profissional e regime de trabalho; descrição da biblioteca e laboratórios; relação de computadores à disposição dos cursos; número máximo de alunos por turma; relação de cursos reconhecidos e de cursos em processo de reconhecimento; conceitos obtidos nas últimas avaliações realizadas pelo MEC; valor corrente das mensalidades por curso ou habilitação; valor corrente das taxas de matrícula e outros encargos financeiros a serem assumidos pelos alunos.

3. Por exemplo, Di Genio, empresário, dono e reitor da Unip - Universidade Paulista, a maior universidade do Brasil em termos de número de alunos, com 53 mil alunos em 1999, levantou seu império preenchendo lacunas deixadas pelo ensino público. Oyama e Manso (1999) apontam o preenchimento de três lacunas: a) implantou uma universidade descentralizada, em contraste com a USP que centraliza a maioria de seus cursos num único campus, dificultando o acesso dos alunos em termos de locomoção; b) oferece um número maior de vagas no processo de admissão, tornando mais fácil o ingresso a essa instituição de ensino; c) concentra $70 \%$ de seus cursos no período noturno, facilitando os estudos para os alunos-trabalhadores, enquanto as universidades públicas federais concentram $85 \%$ de seus cursos apenas durante o dia.

\section{REFERÊNCIAS BIBLIOGRÁFICAS}

ALMEIDA, C.R. O brasão e o logotipo. Um estudo das novas universidades na cidade de São Paulo. Tese de doutoramento. São Paulo, Faculdade de Educação da Universidade de São Paulo, 1997.

CALLEJA, T. La universidad como empresa: una revolución pendiente. Madrid, Ediciones Rialp, 1990.

CANCLINI, N.G. Consumidores y ciudadanos - conflitos multiculturales de la globalización. Mexico D.F., Editorial Grijalbo, 1995.

CHARLE, C. e VERGER, J. História das universidades. São Paulo, Editora da Unesp, 1996.

DURHAM, E. e SAMPAIO, H. "La educación privada en Brasil". In: SCHWARTZMAN, S. (org.). América Latina: universidades en transición. Washington, n.61, OEA/OAS, 1996 (Colección Interamer).

FÁVERO, M. de L. "Autonomia Universitária e Educação Superior no Brasil”. In: MOROSINI, M. (org.). Mercosul/Mercosur: políticas e ações universitárias. Campinas, Autores Associados, 1998, p.196-204.

GEIGER, R. Private sectors in higher education. Struture, funcion and change in eight countries. Michigan, The University of Michigan Press, 1986.

JARDILINO, J.R. e SANTOS, E. "Universidade e marketing: um estudo sobre a rede particular de educação superior da cidade de São Paulo". Eccos Revista Científica. São Paulo, Centro Universitário Nove de Julho, v.1, n.1, dez. 1999, p.129-144

LEVITT, T. A imaginação de marketing. São Paulo, Atlas, 1985.

MARTINS, C.B. Ensino pago: um retrato sem retoques. São Paulo, Editora Global, 1981.

OYAMA, T. e MANSO, B. "O dono do ensino". Revista Veja. São Paulo, Editora Abril, 01/set./1999.

SAMPAIO, H. O setor privado de ensino superior no Brasil. Tese de doutoramento. São Paulo, Programa de Ciência Política da Faculdade de Filosofia, Letras e Ciências Humanas da Universidade de São Paulo, 1998

SCHWARTZMAN, S. La universidad como empresa económica. Texto apresentado no Seminário "El papel de las universidades en el desarrollo social”. Valdívia, Universidade Austral de Chile, março 1996, mimeo.

. O ensino superior no Brasil-1998. Brasília, Inep, n.6, 1999 (Texto para discussão).

SILVA Jr., J. dos R. e SGUISSARDI, V. Novas faces da educação superior no Brasil. Reforma do Estado e mudança na produção. Bragança Paulista, Editora da Universidade São Francisco, 1999.

TACHIZAWA, T. e ANDRADE, R.O. Gestão de instituições de ensino. São Paulo, Editora Fundação Getúlio Vargas, 1999. 